\section{EFSUMB Fellows}

At the Board of Delegates Meeting at EUROSON 2016 the following EFSUMB members were approved as Fellows for their substantial contribution to the field of ultrasound over a prolonged period:

Svein Ødegaard, Norway, Klaas Bom, The Netherlands, Lorenzo Derchi, Italy and Diana Gaitini, Israel

\section{EFSUMB Best Published Paper Prize \\ $\nabla$}

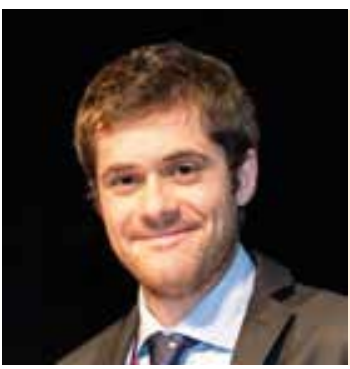

Gitto

Salvatore

The winner of the best published paper prize of $500 €$ submitted in the last 2 years was awarded to Gitto Salvatore, Italy for the paper 'Normal Sonographic Anatomy of the Wrist with Emphasis on Assessment of Tendons, Nerves, and Ligaments' published in J Ultrasound Med 2016; 35:e15-e28
Winners of the EFSUMB Young Investigator Award at EUROSON 2016 $\nabla$

Best technical presentation

Emiel van Disseldorp - The Netherlands

Patient-Specific Mechanical Characterization of Abdominal Aortic Aneurysms using 4D Ultrasound

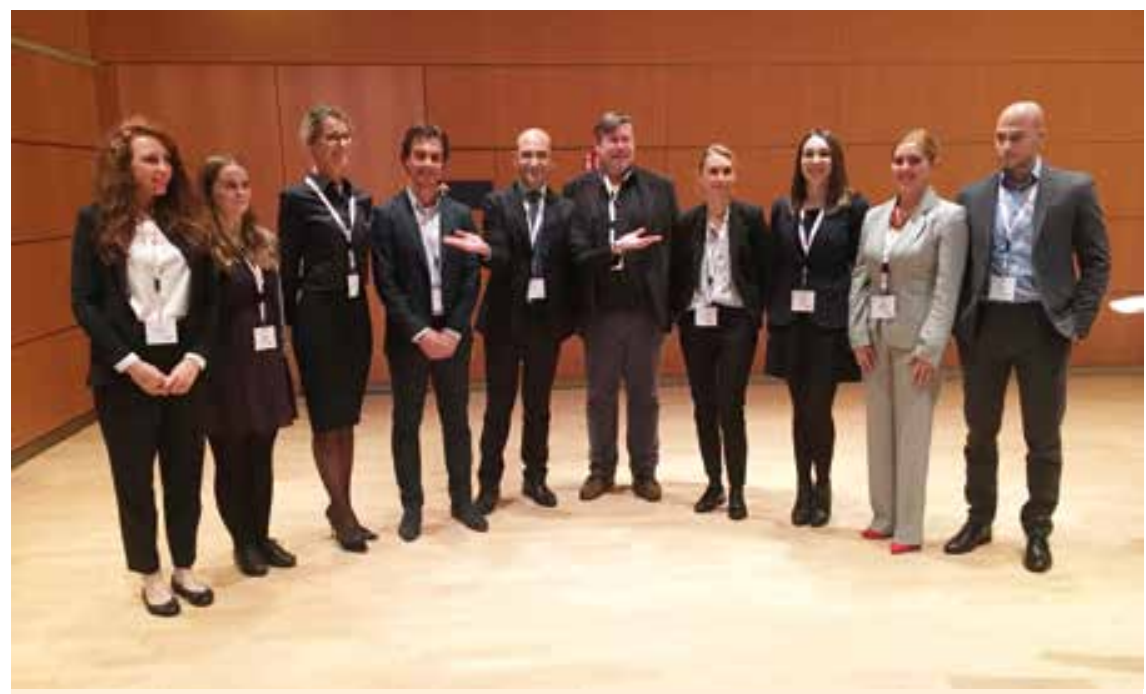

Left to right: Annabianca Amoruso (IT), Belinda Gorell (UK), Anesa Mulabecirovic (NO), Emiel van Disseldorp (NL), Vito Cantisani (Chair), Michael Bachmann Nielsen (Chair), Malene R Pedersen (DK), Ruxandra Mare (RO), Gokce Akgunduz (TR) and Kaloyan Pavlov (BG). Not in the photograph Antanas Budènas (LT) 